\section{P158 EVALUATION OF SEXUAL HEALTH SERVICE USE AT BASELINE (2014) IN SOUTH EAST LONDON}

${ }^{1}$ Katy Turner*, 'Katharine Looker, ${ }^{2} J$ onathan Syred, ${ }^{2}$ Sharmani Bernard, ${ }^{2}$ Paula Baraitser ${ }^{1}$ University of Bristol, Bristol, UK, ${ }^{2}$ Kings College London, London, UK

10.1136/sextrans-2016-052718.208

Background/introduction Lambeth and Southwark have poor sexual health outcomes compared with the rest of England. We wished to evaluate an intervention to improve access to sexual health services through online STI testing and contraceptive provision.

Aim(s)/objectives This study describes baseline service use in Lambeth and Southwark in 2014 prior to the introduction of online services. We present our methodology for evaluating service use across the boroughs.

Methods We collated baseline demographic and clinical data from all sexual health service providers (genitourinary medicine and community sexual health clinics) in Lambeth/Southwark, South East London, for one calendar year (2014). Individual level clinic data were merged, together with Office for National Statistics (ONS) on index of multiple deprivation for area (LSOA) of residence. We summarise the main type of service used and define each attendance as possible to be provided "online" (basic STI test, repeat oral contraception) or requiring "offline" services (e.g. clinical exam, surgical intervention, symptoms, long-acting contraception).

Results We collected over 127,000 attendance records for sexual health services in Lambeth and Southwark during 2014. All clinics reported consistent levels of activity during each quarter. Up to $40 \%$ of attendances could potentially be provided online based on clinic coding.

Discussion/conclusion The low monthly variation in attendances suggests that current services are operating at capacity. Understanding current service use will enable evaluation of online services to assess whether providing online services 1) increases capacity, 2) reaches new population groups 3) improves access for high risk groups.

\section{P159 INCREASING USER INVOLVEMENT AND DIVERSITY IN HIV RESEARCH. A PATIENT QUESTIONNAIRE SURVEY}

Kaja Widuch*, Rebecca O'Connell. Newham Hospital, Barts Health, London, UK

\subsection{6/sextrans-2016-052718.209}

Background/introduction Engaging people living with HIV in developing and participating in research is essential for improving quality of care and evidence based practice. Women and black and minority ethnic groups (BME) remain underrepresented in HIV research. Barriers to HIV research participation are underexplored.

Aim(s)/objectives To explore: i) barriers to participation ii) research preferences in our HIV clinic population- majority female and set in a socioeconomically vulnerable and diverse population.

Methods We developed a self-administered paper questionnaire which was reviewed by two patient representative organisations by email and group discussion. Questionnaires were completed in clinic November 2015 - March 2016.

Results From a cohort of approximately 1000 patients, 765 attended in the study period and 157 (20.5\%) participated: 79 (50.3\%) female; 81 (51.6\%) black ethnicity, 41 (26.1\%) white. Research participation: $74(47.1 \%)$ had previously participated in at least one study; 118 (75.1\%) would consider future participation. Research preferences: $66(42.0 \%)$ patients expressed interest in both medical and social research, 60 (38.2\%) medical and 17 (10.8\%) social. Incentives: 69 (43.9\%) were more likely to participate if incentives available; $62(39.5 \%)$ were unsure whether incentives would influence participation; 21 (13.4\%) said it would not. Travel: $60(38.2 \%)$ patients were unsure whether they would travel to another clinic for research, 36 $(22.9 \%)$ would travel and $33(21.0 \%)$ would not. For 22 (14.0\%) respondents, clinic location would influence a decision to participate. Barriers to participation: 51 (32.4\%) fear of HIV disclosure; $52(33.1 \%)$ fear of something going wrong; 45 $(28.7 \%)$ time constraints.

Discussion/conclusion Our survey suggests that raising research awareness and disseminating information addressing fears and barriers could potentially increase research participation in our clinic.

\section{P160 IDENTIFICATION AND CHARACTERISTICS OF WOMEN WITH FEMALE GENITAL MUTILATION PRESENTING TO SEXUAL HEALTH SERVICES}

${ }^{1} J o a n n e$ Buckley, ${ }^{1}$ Emma Thorman, ${ }^{2}$ Helen Jones, ${ }^{1}$ Elizabeth Hamlyn*. ${ }^{1}$ Kings College Hospital, London, UK; ${ }^{2}$ Kings College London, London, UK

\subsection{6/sextrans-2016-052718.210}

Background/introduction Female Genital Mutilation (FGM) is illegal in the UK. When identified, it is mandatory to record FGM in a patient's health care record and to report under $18 \mathrm{~s}$ to the police.

Aim(s)/objectives To investigate characteristics and management of patients with FGM attending an inner city sexual health service.

Methods Retrospective case note review of patients recorded as having had FGM between February 2014 and November 2015.

Results 65 patients were identified; 52 attended the walk-in GUM clinic and 13 attended the HIV clinic. Median age was 33 years (range 17-54 years). Common countries of origin were Sierra Leone, Somalia and Nigeria in 38\%, 20\% and 12\%, respectively. Most FGM took place in childhood (aged 0-4 years in $17 \%$, aged $5-10$ years in $37 \%$, aged $10-15$ years in $11 \%$ ). FGM was self-reported in $13(20 \%)$ and identified during examination in $52(80 \%)$ patients. Type 1 and 2 FGM were the most common forms in $21(32 \%)$ and 29 (45\%), respectively. Of 52 cases presenting to GUM, 28 (54\%) were first attendances. Of the remaining, 15/24 (63\%) cases of FGM had not been identified on previous visits despite a previous documented examination in 11/15 (73\%). One patient was under 18 at presentation and $18(28 \%)$ had daughters or sisters aged $<18$ years. Immediate safeguarding concerns were raised in 4 cases. Discussion/conclusion FGM is common yet frequently missed by health care professionals even during examination. Training in the recognition and management of FGM is essential for staff working in Sexual Health.

\section{P161 MANAGING SEXUAL ASSAULT IN AN INTEGRATED SEXUAL HEALTH SERVICE: ENSURING QUALITY AND PATHWAYS INTO CARE}

Joanne Hamilton, Tatyana Sahabandu, Justine Orme*, Suneeta Soni, Daniel Richardson. Brighton and Sussex University Hospitals, Brighton, UK

10.1136/sextrans-2016-052718.211 